\title{
Review: high dose vitamin E supplementation is associated with increased all cause mortality
}

Miller ER 3rd, Pastor-Barriuso R, Dalal D, et al. Meta-analysis: high-dosage vitamin E supplementation may increase all-cause mortality. Ann Intern Med 2005; 142:37-46.

\section{Q Does vitamin E supplementation increase all cause mortality? Does a dose-response relation exist between vitamin E and all cause mortality?}

\section{METHODS}

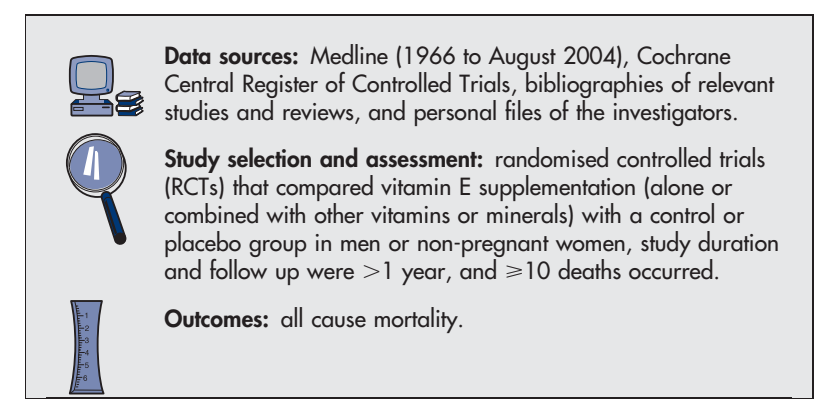

\section{MAIN RESULTS}

19 RCTs ( $\mathrm{n}=135$ 967, mean age range $47-84$ y) met the selection criteria. 9 RCTs evaluated vitamin E alone, and 10 combined vitamin E with other vitamins or minerals. 16 RCTs were placebo controlled. Vitamin E dose varied between 16.5 and 2000 IU/d. Overall, vitamin E supplementation did not affect all cause mortality (table). However, although mortality was not increased in 8 RCTs evaluating low dose vitamin $\mathrm{E}$, high dose vitamin $\mathrm{E}$ was associated with increased mortality (11 RCTs) (table). A dose-response analysis showed that all cause mortality increased as vitamin E dose increased to $>150 \mathrm{IU} / \mathrm{d}$. The effect of vitamin E did not change after adjustment for differences in sex, mean age, or mean follow up. The association of high dose vitamin $\mathrm{E}$ and mortality was stronger after adjustment for simultaneous use of other vitamins and minerals (pooled relative risk $1.06,95 \%$ CI 1.01 to 1.11 ; risk difference 63 per 10000 persons, CI 6 to 119).

\section{CONCLUSIONS}

High dose ( $\geqslant 400 \mathrm{IU} / \mathrm{d}$ ) vitamin E supplementation is associated with increased risk of all cause mortality. A dose-response relation exists between vitamin $\mathrm{E}$ doses $>150 \mathrm{IU} / \mathrm{d}$ and mortality.

For correspondence: Dr E R Miller 3rd, Johns Hopkins Medical Institutions, Baltimore, MD, USA. ermiller@jhmi.edu

Sources of funding: in part, Instituto de Salud Carlos III.
A modified version of this abstract appears in ACP Journal Club.

\section{Commentary}

$\Lambda$ t least $22 \%$ of older adults in the US take a vitamin E supplement, often at high doses. ${ }^{1}$ The meta-analysis by Miller et al provides evidence that such high doses of vitamin $\mathrm{E}$ are harmful. However, in the trials analysed, high dose vitamin $\mathrm{E}$ was often used in patients with chronic illness, so the effect of concomitant medication may have influenced the findings. Similarly, studies of low dose vitamin E were often done in malnourished populations, making it difficult to extrapolate the finding of increased mortality at higher doses to the general population. Many of the trials used vitamin $\mathrm{E}$ in addition to other supplements, such as $\beta$ carotene. Although Miller et al controlled for the possible effects of other supplements, the higher mortality rate among those using high dose vitamin $\mathrm{E}$ may have been influenced by the combined effect of nutritional status, other medications, and concurrent administration of other vitamin supplements. None of the studies analysed seemed to differentiate between natural and synthetic sources of vitamin $E$, which could be a confounding variable.

Despite these limitations, the results of this review are important to nurses working with patients with chronic illnesses, public health nurses, and those working in primary care. Based on these findings, it may be prudent to advise patients, especially those with chronic illness, to avoid high dose vitamin E supplementation because the risk of harm may outweigh any perceived benefit. Further study is needed to determine the effects of individual vitamin supplements on various populations. Intuitively, vitamins are often assumed to be safe-this study suggests that, as with prescribed medications, more is not necessarily better, or indeed safe.

Claudia Mariano, RN(EC), MSc Primary Health Care Nurse Practitioner East End Community Health Centre Toronto, Ontario, Canada

1 Millen AE, Dodd KW, Subar AF. Use of vitamin, mineral, nonvitamin, and nonmineral supplements in the United States: the 1987, 1992, and 2000 National Health Interview Survey results. J Am Diet Assoc 2004;104:94250 .

High dose $(\geqslant 400 \mathrm{IU} / \mathrm{d})$, low dose $(<400 \mathrm{IU} / \mathrm{d})$, and all doses of vitamin $\mathrm{E}$ supplementation $v$ placebo or no vitamin $\mathrm{E}$ for all cause mortality*

\begin{tabular}{|c|c|c|c|c|}
\hline Number of trials (n) & Vitamin E dose & RRI $(95 \% \mathrm{Cl})$ & $\begin{array}{l}\text { Risk difference } \\
\text { per } 10000 \text { persons (CI) }\end{array}$ & NNH (Cl) \\
\hline \multirow[t]{2}{*}{$\begin{array}{l}19(135967) \\
11(40950)\end{array}$} & $\begin{array}{l}\text { High and low } \\
\text { High }\end{array}$ & $\begin{array}{l}1 \%(-2 \text { to } 4) \\
4 \%(1 \text { to } 7)\end{array}$ & $\begin{array}{l}10(-18 \text { to } 38) \\
39(3 \text { to } 74) \dagger\end{array}$ & $\begin{array}{l}\text { Not significant } \\
257 \text { (136 to 3334) }\end{array}$ \\
\hline & & RRR (Cl) & & NNT \\
\hline 8 (95 017) & Low & $2 \%(-1$ to 4$)$ & $-16(-41$ to 10$)$ & Not significant \\
\hline
\end{tabular}

*Abbreviations defined in glossary; RRI, RRR, NNH NNT, and Cl calculated from data in article. Follow up ranged from 1.4 to 8.2 years. A dose-response regression model was used.

†Favours placebo or no vitamin $\mathrm{E}$. 